\title{
Redes de suporte social e (in)acesso a direitos em famílias monoparentais femininas
}

\author{
Social support networks and the (in) access to social rights in female single-parent \\ families
}

\section{Sonia Guadalupe* Sandra Tavares** Rosa Monteiro***}

\begin{abstract}
Resumo:
O estudo caracteriza as redes de suporte social e o (in)acesso a direitos de famílias monoparentais femininas em situação de vulnerabilidade social. A amostra de 29 mulheres beneficiárias de um banco de recursos da zona centro de Portugal, é constituída na maioria por mães divorciadas, com idades entre os 18 e os 61 anos, com baixos níveis de escolaridade e predominantemente desempregadas. Os resultados revelam desproteção familiar, sendo que a maioria não beneficia de direitos consagrados, experienciando privação material. As redes de suporte informal são pequenas e coesas, centradas nas relações familiares, verificando-se uma forte reciprocidade nos níveis moderados de apoio emocional e baixos de apoio material/instrumental e informativo, não representando um apoio compensatório da situação de vulnerabilidade social. Urgem políticas públicas que potenciem uma efetiva proteção social das mulheres e crianças desta configuração familiar e estratégias de intervenção emancipadoras que ultrapassem a iliteracia em direitos e favoreçam a cidadania.
\end{abstract}

Palavras-chave: Monoparentalidade. Vulnerabilidade social. Rede de suporte social. Iliteracia em direitos.

\begin{abstract}
:
The study characterizes social support networks and the access to social rights of socially vulnerable female single-parent families. A sample of 29 women beneficiaries of a social service of central Portugal, consists mostly of divorced mothers, aged 18 to 61 years old, with low levels of education and predominantly unemployed. The results reveal family unprotected, who are not benefiting from recognized rights, experiencing material deprivation. The informal support networks are small and cohesive, focused on family relationships, with a strong reciprocity but moderate levels of emotional support and low material/instrumental and informative support, and does not represent a compensatory support of the vulnerability. Urge public policies that foster effective social protection of women and children in this family configuration and emancipatory intervention strategies beyond illiteracy on rights that promote citizenship.
\end{abstract}

\footnotetext{
* Assistente Social; Mestre em Família e Sistemas Sociais; Doutorada em Saúde Mental; Doutoranda em Serviço Social. Professora do Instituto Superior Miguel Torga.E-mail: guadalupe@ismt.pt

** Assistente Social; Mestre em Psicologia Clínica. E-mail: sandratavares78@hotmail.com

*** Socióloga; Doutorada em Sociologia. Professora do Instituto Superior Miguel Torga. E-mail: monteiro.rosa14@gmail.com
} 
Keywords: Single parenthood. Social vulnerability. Social support network. Illiteracy on rights.

\section{Introdução}

As famílias monoparentais têm sido identificadas como sendo das mais vulneráveis à pobreza (CÓRDON; SOLER, 1998; COSTA et al., 2008; PEREIRINHA et al., 2008). Wall (2003) associa essa vulnerabilidade ao fato desta configuração familiar ser marcada pela feminização, constituída sobretudo por mães sós com crianças.

Em Portugal, os registos demográficos apontam que, entre os tipos de família clássicos (com um indivíduo, casal sem filhos, casal com filhos, monoparental e outros), a família monoparental seja a que apresenta uma menor proporção, mas a tipologia tem vindo a aumentar em números absolutos e relativos, tendo os núcleos familiares monoparentais passado de 6\%, em 1960, para 9\%, em 2011 (INSTITUTO NACIONAL DE ESTATÍSTICA, 2013).

Segundo dados dos Censos do Instituto Nacional de Estatística (INE; PORDATA), tínhamos em 2001 um total de 273.712 famílias monoparentais ${ }^{1}, 7,7 \%$ das famílias clássicas, em que os agregados de "mãe com filhos" representavam 6,5 vezes o número de casos de "pai com filhos". Mas o número e a proporção de famílias monoparentais nas famílias clássicas tem registado um aumento continuado sempre com uma maioria marcada pelo sexo feminino na parentalidade. Nos Censos portugueses de 2011, registavam-se 398.170 agregados, $87,3 \%$ femininos, representando $10 \%$ das famílias clássicas, o que significa um aumento de $45 \%$ famílias monoparentais entre registos censitários. A constatação do aumento exponencial do número de famílias com apenas um dos progenitores com os seus filhos (CORREIA, 2002; PEREIRINHA et al., 2008; WALL; LOBO, 1999) traz novos desafios a quem investiga e intervém com famílias (VAZ; RELVAS, 2002), representando um "alvo privilegiado não só de trabalhos de investigação mas também das políticas públicas de apoio à família" (WALL, 2003, p. 51).

\footnotetext{
${ }^{1}$ O INE, Instituto Nacional de Estatística (Portugal) classifica como família monoparental o "núcleo familiar que integra apenas um dos progenitores, pai ou mãe, com filho(s)". Em 2001 definia-a como "núcleo familiar monoparental" um "conjunto de pessoas dentro de uma família clássica que tem a presença de apenas um dos progenitores, pai, ou mãe com filho(s), avó ou avô com neto(s) não casado(s)" (Fonte: metainformação - INE, Portugal).
} 
Quando se fala de família monoparental, reportamo-nos à ideia de maternidade e paternidade dita simples, fazendo referência à relação com os filhos por parte de mães ou pais educadores únicos, solteiros, viúvos ou divorciados, ou remetemos a uma "estrutura familiar onde uma ou mais crianças vivem com apenas um dos progenitores ou alguém que, na qualidade de tutor, assuma esse papel" (GOMES, 2003, p. 8), ou ainda a "uma mãe ou um pai a viver sem cônjuge e com filhos dependentes (crianças ou jovens adultos solteiros)" (WALL, 2003, p. 51).

Alarcão (2002) designa por monoparentais as famílias nas quais a geração dos progenitores está apenas representada por um único elemento, o que pode acontecer por diversas situações, como a viuvez, a ruptura conjugal, o celibato e a ausência/emigração do cônjuge, sendo uma estrutura familiar que não é criada com a junção de novos elementos, mas geralmente a partir de rupturas na conjugalidade (VAZ; RELVAS, 2002) ou após um acontecimento vital, tal como o falecimento de um cônjuge, mas também no caso da assunção isolada da maternidade ou da paternidade.

Wall e Lobo (1999) fazem a distinção entre monoparentalidade tradicional e monoparentalidade por ruptura conjugal, afirmando que a primeira explica-se com base em três causas: o falecimento de um dos cônjuges, a procriação de filhos fora do casamento e a ausência ou a emigração do cônjuge; a segunda deve-se essencialmente às mudanças de perspectiva em face ao divórcio, ideia corroborada por Torres (1996), quando faz uma analogia entre o aumento de número de pais e de mães separados ou divorciados com filhos a seu cargo, com o crescimento progressivo da separação e do divórcio na sociedade portuguesa.

O estado civil é tido como uma das variáveis-chave para a compreensão da diversidade das famílias monoparentais, tipificando-se três situações distintas em Portugal (WALL; LOBO, 1999): 1) pais e mães sós, geralmente viúvos(as), em especial mulheres, que vivem com filhos adultos pouco inseridos no mercado de trabalho; 2 ) mães solteiras, com idade inferior a 24 anos, que vivem sozinhas com um filho menor e com elevada participação no mercado de trabalho (em duas situações: com ou sem pensão de alimentos); 3) mães e pais divorciados, a viver com um ou dois filhos, com um elevado nível de instrução e bem inseridos no mercado de trabalho. Até a mudança legislativa de 2008, que pugna pela partilha das responsabilidades parentais como regra, quando se verificava 
uma separação ou divórcio, estas eram, na maioria das situações, assumidas pelas mães, quase sempre ficando com os filhos à sua guarda (WALL; LOBO, 1999).

Um traço marcante da monoparentalidade em Portugal deve-se ao fato de ela ser uma situação essencialmente vivida no feminino (MARINHO, 2014; PEREIRINHA et al., 2008; PERISTA; GOMES; SILVA, 1992; WALL; LOBO, 1999). A feminização dessas famílias pode ser assim conceptualizada como uma dimensão da sua fragilidade social. Pereirinha et al. (2008) sublinham mesmo que estes agregados são particularmente vulneráveis à pobreza, uma vez que muitos deles dependem exclusivamente do rendimento materno. Aliás, o fenômeno da pobreza é sensível a variáveis como o grupo etário - maior incidência em crianças e idosos - e sexo - feminização da pobreza (PEREIRINHA et al., 2008). Sublinhando essa ideia, Costa et al. (2008, p. 111) afirmam que "existe uma certa feminização da pobreza, na medida em que é maior a vulnerabilidade à pobreza nos agregados que têm por representante uma mulher, além de que, entre os pobres, as mulheres representam uma proporção comparativamente maior". Tal também se verifica ao nível da União Europeia, sendo que o relatório da Rede Europeia Anti-Pobreza/Portugal (REAPN, 2009), relativo a 24 estados membros, refere que existem quatro grupos que se destacam pelo elevado risco de pobreza, sendo um deles constituído por pessoas em idade ativa a viver sozinhas com crianças a cargo (na sua maioria mulheres).

Por conseguinte, Torres (1989) e Perista, Gomes e Silva (1992) afirmam que o universo feminino é mais vulnerável às situações de pobreza, destacando-se quatro fatores que podem contribuir para o seu agravamento: 1) a maior concentração das mulheres em postos de trabalho de baixo estatuto profissional e remuneratório; 2) a concentração na mulher da função provedora de rendimentos, situação que pode inclusivamente favorecer a inserção precoce das crianças em atividades remuneradas (CARVALHO, 1998); 3) as dificuldades de conciliação e de acomodação por parte das mulheres das suas várias funções (familiares, domésticas, profissionais) e o maior condicionamento na "escolha", sujeitando-se geralmente a trabalhos mal remunerados; 4) gravidez precoce e consequente instabilidade familiar, que tende a contribuir para a reprodução da pobreza trangeracionalmente (TORRES, 1989). O Relatório da Unicef $(2013$, p. 14) sobre pobreza infantil em Portugal, na análise das taxas de pobreza de 2011, é inequívoco ao evidenciar que "as famílias numerosas (com três ou mais crianças) e as famílias monoparentais (pai 
ou mãe só com filho/s) são os agregados com maior risco de pobreza - 30,7\% e 41,2\% respectivamente".

Vitale (2002) e Pacheco (2005) evidenciam também uma relação estreita entre pobreza e chefia familiar feminina, sublinhando tal tendência em países da América Latina, assim como nos Estados Unidos da América. A monoparentalidade feminina pode, assim, favorecer processos de exclusão social, constituindo-se como um dos seus fatores (TORRES 1989; FERREIRA; ABOIM, 2002; GERARDO, 2004).

Noutro ângulo, Perista, Gomes e Silva (1992) consideram que as famílias pobres tendem a afastar-se do modelo dominante da família conjugal, centrada e reduzida ao núcleo de pais e filhos solteiros, apresentando frequentemente casos de monoparentalidade, entre outras configurações. Kaufmann (1990) diz que a monoparentalidade é, em certos casos, o próprio exemplo de uma nova modalidade de entrada na pobreza a partir de fatores familiares, ou de reprodução de pobreza. Nessa linha de pensamento, Perista, Gomes e Silva (1992, p. 34) referem que "as mulheres estão expostas a um risco de pobreza duplo, na medida em que a sua posição no mercado de trabalho é mais débil [...] são economicamente mais vulneráveis em face à separação ou ao divórcio". Przybysz (2009) aborda outro determinante que agrava essa vulnerabilização, que consiste nas limitações de acesso à justiça pelas mulheres com baixos rendimentos, assim como o desamparo das políticas públicas relativamente à pobreza infantil. Marsha, Weinraub, e Wolf (apud GOLOMBOK, 2000) demonstraram que as consequências negativas da existência de um só elemento educador advêm de baixos níveis econômicos, do baixo suporte social e dos altos níveis de stress aos quais estão sujeitos, a que pode juntar-se a falta da existência de uma rede social de suporte que apoie o elemento educador.

Não podemos, no entanto, generalizar a associação entre a monoparantalidade e a pobreza. Mas se nas famílias com maiores recursos econômicos e socioprofissionais a monoparentalidade é muitas vezes uma opção e as dificuldades são ultrapassadas, as famílias com menores recursos tendem a viver a situação de monoparentalidade de forma mais negativa e estigmatizada, sobretudo quando as mulheres apresentam baixas qualificações e rendimentos, recaindo os encargos familiares exclusivamente sobre estas (LOYOLA, 2003). 
A relação entre a família e o trabalho é um eixo determinante do quotidiano da vida dessas famílias. A conciliação dos tempos necessários ao desempenho das tarefas profissionais e das funções familiares influencia a qualidade de vida de todos os elementos do agregado doméstico, pois as exigências do cuidado das crianças limitam as hipóteses de quando e onde a mulher pode trabalhar (PERISTA; GOMES; SILVA, 1992). E isso quando, na perspectiva de Sorensen (1990), para ter o mesmo nível de vida, uma família monoparental precisa de muito mais rendimento per capita do que uma família biparental.

Francisco Branco (2001) fez um estudo acerca dos requerentes do Rendimento Mínimo Garantido (designado atualmente como Rendimento Social de Inserção), concluindo que a maioria das famílias monoparentais vivia em casa dos pais $(34,7 \%)$ ou de familiares $(54,2 \%)$, sendo que $26 \%$ viviam em habitações precárias ou degradadas e sem condições básicas. Nesse mesmo estudo, Branco (2001) constatou uma instabilidade das relações e das formas familiares associada a diversos fatores, sendo um deles as constantes rupturas familiares que dão origem às famílias monoparentais. Uma das consequências dessa instabilidade referida no estudo é a competência dessas famílias na socialização das crianças que é posta em causa (BRANCO, 2001). Também para Relvas (1996), as famílias monoparentais de meios mais desfavorecidos nem sempre apresentam condições para cumprir satisfatoriamente a função de socialização, considerando Córdon e Soler (1989), que tal se constitui como um fator de risco de pobreza e de exclusão social, especialmente para os filhos.

No relatório anual do Rendimento Social de Inserção de 2008 (INSTITUTO DA SEGURANÇA SOCIAL, 2009, p. 11), entre os 135.422 titulares da medida,

a tipologia predominante dos agregados familiares beneficiários do RSI correspondia às famílias nucleares com filhos (29\%), seguiam-se os isolados (agregados apenas com um elemento), com $24 \%$ e as famílias monoparentais, com um peso relativo de $21 \%$. As famílias nucleares sem filhos constituíam $9 \%$ dos agregados e as extensas/alargadas apenas $6 \%$.

Mas assinala este relatório do Instituto da Segurança Social - ISS (2009) que em 2008, em face aos dados dos Censos de 2001, verificam-se

diferenças consideráveis em relação à tipologia de famílias monoparentais, onde o peso relativo das famílias beneficiárias RSI era superior ao nacional, tendência observada desde o início da medida, assim como eram superiores os valores relativos aos isolados e às famílias alargadas. 
Também em um estudo de Eduardo Vítor Rodrigues (2010) com 384 titulares da medida no município de Vila Nova de Gaia (Portugal), 21,9\% eram famílias monoparentais, a terceira tipologia é a família nuclear com filhos $(37 \%)$ e a excedente $(25,6 \%)$. Tal consolida a ideia da especial vulnerabilidade e dos problemas sociais que atingem essas famílias.

Podemos considerar que a diminuição de rendimentos, as dificuldades de conciliação da vida profissional com a vida familiar, a ruptura com o progenitor que sai de casa são realidades comuns, mas, apesar dos desafios, e rejeitando uma compreensão linear, é importante salientar que a família monoparental não é necessariamente uma família em risco, ainda que possa configurar uma situação de vida que expõe ao risco social. Dependerá do modo como a(s) ruptura(s) é(são) gerida(s) e das circunstâncias contextuais que as colocam perante outras problemáticas sociais associadas que aumentam o grau de vulnerabilidade dessas famílias, nomeadamente a precariedade econômica (WALL; LOBO, 1999).

Posto isto, o objetivo do nosso estudo consiste em conhecer o perfil das famílias monoparentais sinalizadas em situação de vulnerabilidade social, caracterizando a sua rede social de suporte e o (in)acesso aos seus direitos de proteção social.

\section{Método}

No sentido de operacionalizar os objetivos, traçamos um desenho de investigação descritiva do tipo quantitativa, tendo como variáveis centrais as características sociodemográficas, o contexto da monoparentalidade, o acesso aos direitos e a rede de suporte social formal e informal (TAVARES, 2009).

Neste estudo, foram utilizados, como instrumentos de recolha de dados, um inquérito por questionário e o Instrumento de Análise da Rede Social Pessoal (IARSP). inquérito por questionário teve como objetivo caracterizar as famílias da amostra a níveis sociodemográfico, socioprofissional e sociofamiliar, abrangendo também questões sobre a situação de monoparentalidade, as circunstâncias no cuidar dos filhos, fatores associados à situação de monoparentalidade e proteção social. Esse inquérito foi construído especificamente para servir aos objetivos desta investigação, partindo de um estudo anterior de uma das investigadoras (TAVARES, 2006; 2009). O IARSP (GUADALUPE; 
ALARCÃO, apud GUADALUPE, 2009) permite analisar as características estruturais, funcionais e contextuais das redes de suporte social, tendo sido adaptado para o estudo, utilizando um gerador de rede genérico: "indique o nome das pessoas com que se relaciona, são significativas na sua vida e a apoiam".

A amostragem foi efetuada num Banco de Recursos num concelho do distrito de Coimbra (Portugal), que é uma resposta social do município para a população a vivenciar privação material. Num total de 200 famílias beneficiárias, na sua configuração quanto à composição, 68 eram nucleares; 47, monoparentais; 30, reconstituídas; 30, isoladas; e 25, alargadas. As famílias nucleares representavam, assim, $23 \%$ do total das famílias beneficiárias. Para este estudo, recolheu-se uma amostra não probabilística constituída por 29 famílias monoparentais femininas (nessa situação há pelo menos 1 ano) beneficiárias da resposta social.

A amostra é, assim, constituída por 29 mulheres de famílias monoparentais, residentes no concelho de Cantanhede, em sua maioria divorciadas $(55,2 \%$, acrescidas de 10,3\% separadas). A idade das inquiridas é de 38 anos, em média, e quando do nascimento do filho mais velho era de 20 anos, variando a idade entre os 16 e os 29 anos, sendo que 4 inquiridas tiveram o seu primeiro filho com idade inferior a 18 anos. Tais mulheres têm entre 1 e 5 filhos, sendo que a maioria das respondentes tem 1 filho $(62,1 \%$; $n=18), 20,7 \%$ $(n=6)$ tem 2 filhos, 10,3\% ( $n=3)$ tem 3 filhos e há um caso com 4 e outro com 5 filhos.

Tabela 1 - Características sociodemográficas

\begin{tabular}{|c|c|c|}
\hline & $n=29$ & $100 \%$ \\
\hline & $n$ & $\%$ \\
\hline \multicolumn{3}{|l|}{ Estado Civil } \\
\hline Solteira & 6 & 20,7 \\
\hline Viúva & 4 & 13,8 \\
\hline Divorciada & 16 & 55,2 \\
\hline Separada & 3 & 10,3 \\
\hline \multicolumn{3}{|l|}{ Nível de escolaridade } \\
\hline Sem escolaridade & 1 & 3,4 \\
\hline 1ํ Ciclo do ensino básico & 13 & 44,8 \\
\hline 2ํ Ciclo do ensino básico & 10 & 34,5 \\
\hline 3 Ciclo do ensino básico & 4 & 13,8 \\
\hline Ensino secundário & 1 & 3,4 \\
\hline \multicolumn{3}{|l|}{ Condição Perante o Trabalho } \\
\hline Empregada & 10 & 34,5 \\
\hline Desempregada & 18 & 62,1 \\
\hline Doméstica & 1 & 3,4 \\
\hline \multicolumn{3}{|c|}{ Principal Fonte de Rendimentos } \\
\hline Sem rendimentos & 2 & 6,9 \\
\hline Pensões & 8 & 27,6 \\
\hline
\end{tabular}




\begin{tabular}{lcccc}
\hline RSI - Rendimento Social de Inserção & 9 & \multicolumn{2}{c}{31,0} \\
Trabalho & \multicolumn{2}{c}{3,4} \\
Outras & & 9 & \multicolumn{2}{c}{31,0} \\
\hline & M & DP & Mínimo & Máximo \\
\hline Idade & 38,07 & 11,871 & 18 & 61 \\
Idade da(o) inquirida(o) ao nascimento do 10 filho & 20,34 & 3,352 & 16 & 29 \\
No de filhos & 1,66 & 1,045 & 1 & 5 \\
\hline
\end{tabular}

M (média) DP (desvio-padrão). Fonte dos dados: Inquérito.

Fonte: elaborada pelos autores.

Relativamente ao nível de escolaridade, 79,3\% dessas mulheres têm habilitações abaixo da escolaridade obrigatória, encontrando-se maioritariamente desempregadas $(62,1 \%)$, sendo as profissões desempenhadas pouco qualificadas (agricultura, limpeza, restauração, empregadas fabris e de balcão e auxiliares de ação educativa). Sua principal fonte de rendimentos é o RSI ( $31 \%$ n=9) e pensões de alimentos e de sobrevivência $(27,6 \%$; $n=8) ; 31 \%(n=9)$. Elas referiram também ter outros rendimentos, que são essencialmente ajudas familiares, o subsídio de desemprego e o abono de família. Apenas 1 das inquiridas vive dos rendimentos do trabalho, e há 2 que se declaram sem rendimentos. Convém ainda acrescentar que algumas famílias revelaram que se beneficiavam de apoios combinados. Quanto à habitação, observamos que $27,6 \%(n=8)$ das famílias inquiridas vivem em casa própria, 34,5\% ( $n=10)$ em casa arrendada e 37,9 ( $n=11)$ em habitação cedida, frequentemente por familiares (sobretudo os pais) ou amigos.

\section{Resultados}

\section{Vivência da Situação de Monoparentalidade}

$\mathrm{Na}$ nossa amostra, a principal causa apresentada para a situação de monoparentalidade das famílias inquiridas é o divórcio ou a separação (69\%), acrescidos de 2 casos que referem abandono do companheiro (6,9\%), seguindo-se a viuvez $(13,8 \%)$, enquanto apenas $3(10,3 \%)$ foram "mães solteiras". O tempo de duração da situação de monoparentalidade varia entre 1 e 19 anos, sendo que 44,8\% se encontram há menos de 2 anos em situação de monoparentalidade, 27,5\% há menos de 5 anos e as restantes há 6 anos ou mais. A maioria das inquiridas refere não ter vivido antes outras situações de monoparentalidade (65,5\%). Dos 10 casos que já vivenciaram a monoparentalidade anteriormente, apuramos que 9 foram por divórcio ou separação. A maioria das inquiridas 
$(82,8 \%)$ refere não ter atualmente um envolvimento afetivo com outra pessoa, sendo que 17,2\% mantêm uma relação afetiva estável, sem coabitação.

As mulheres inquiridas reportam essencialmente dificuldades a nível econômico (69\%), a nível emocional (17,2\%) e na educação dos filhos (13,8\%). Quando pedimos que nos indicassem aspectos menos negativos associados à monoparentalidade, 7 (24\%) apontaram a liberdade e $5(17,2 \%)$ o fim da violência doméstica, por exemplo. Nesse conjunto de questões, o objeivo é saber quais as expectativas quanto ao futuro por parte dos inquiridos. Assim, a maioria (51,7\%) imagina um futuro melhor para si e para os filhos, $24,1 \%$ referiram um futuro incerto, $13,1 \%$ manifestaram o desejo de reconstituir família (sendo estes 4 dos 5 inquiridos que mantêm relações afetivas) e 10,3\% mostraram-se mais pessimistas referindo que anteviam um futuro com dificuldades, sobretudo a nível econômico.

\section{O (in)acesso a Direitos de Proteção Social}

Na relação com o outro progenitor dos seus filhos, a maioria das inquiridas $(62,1 \%)$ não recebe pensão de alimentos devida a menores. Destas 18 famílias, 9 afirmam que tal acontece por recusa do seu pagamento, sendo de salientar que em alguns casos os processos se encontravam a decorrer em Tribunal à data da recolha de dados; as outras 9 alegam outros motivos, nomeadamente o receio de eventuais represálias por parte do outro progenitor, assim como o fato de se desconhecer o seu paradeiro.

A maioria das famílias se beneficia de proteção social (69\%), sobretudo da medida do Rendimento Social de Inserção (RSI) (31\%; $n=9)$, que é uma medida de mínimos sociais, de majoração do Abono de Família ${ }^{2}(34,5 \%$; $=10)$, e do Fundo de Garantia dos Alimentos Devidos a Menores, que assegura a Pensão de Alimentos Devidos a Menores ${ }^{3}$ (6,9\%; $n=2$ ).

\footnotetext{
${ }^{2}$ Em Portugal, a nível das políticas públicas, as majorações do abono de família para crianças e jovens e do abono de família pré-natal (famílias com duas ou mais crianças/famílias monoparentais) são um aumento percentual do valor do abono de família, enquadrando-se nas medidas de proteção familiar da Segurança Social.

${ }^{3} \mathrm{Em}$ Portugal, esse fundo pode ser requerido quando a pessoa judicialmente obrigada a prestar alimentos a menor (crianças ou jovens até aos 18 anos de idade) residente em território nacional não satisfizer os seus deveres, sob as condições previstas na lei, o Estado assegura as prestações previstas até ao início do efetivo cumprimento da obrigação, cabendo ao Fundo de Garantia dos Alimentos Devidos a Menores (FGADM) assegurar o pagamento dos alimentos, sendo as prestações fixadas pelo tribunal.
} 


\section{Rede de Suporte Social}

O tamanho da rede é um indicador relevante quando se analisam os aspectos estruturais da rede de suporte social (Tabela 2). As redes de apoio das inquiridas apresentam em média 7 elementos, sendo que $62,1 \%$ das inquiridas apresenta uma rede de suporte social igual ou inferior a este valor.

Tabela 2 - Características Estruturais da Rede de Suporte Social

\begin{tabular}{|c|c|c|c|c|}
\hline$(n=29)$ & & $n$ & & 6 \\
\hline \multicolumn{5}{|l|}{ Densidade da Rede } \\
\hline Rede Coesa & & 23 & \multicolumn{2}{|c|}{79,3} \\
\hline Rede Fragmentada & & 6 & \multicolumn{2}{|c|}{20,7} \\
\hline \multicolumn{5}{|l|}{ Tamanho da Rede (número de membros) } \\
\hline$<=5$ & & 11 & \multicolumn{2}{|c|}{37,9} \\
\hline 6 a 10 & & 12 & \multicolumn{2}{|c|}{41,4} \\
\hline \multirow[t]{2}{*}{$>=11$} & & 6 & \multicolumn{2}{|c|}{20,7} \\
\hline & M & DP & Mínimo & Máximo \\
\hline Tamanho da rede (número de membros) & 7,45 & 3,582 & 3 & 17 \\
\hline \multicolumn{5}{|c|}{ Proporção do tamanho dos campos no tamanho da rede (em \%) } \\
\hline Relações Familiares & 75,34 & 20,274 & 29 & 100 \\
\hline Relações de Amizade & 13,14 & 15,574 & 0 & 50 \\
\hline Relações de Vizinhança & 4,14 & 9,945 & 0 & 40 \\
\hline Relações de Trabalho ou Estudo & 1,55 & 5,804 & 0 & 23 \\
\hline Relações Institucionais & 5,14 & 10,669 & 0 & 43 \\
\hline
\end{tabular}

M (média); DP (desvio-padrão). Fonte de Dados: IARSP-RS

Fonte: elaborada pelos autores.

Ao avaliarmos a proporção que cada um dos campos relacionais ocupa no tamanho da rede, as relações familiares são as que apresentam maior peso (75,34\% em média), seguidas das relações de amizade $(13,14 \%)$, sendo os restantes campos mais residuais.

A densidade da rede permite-nos representar a conexão entre os seus membros, acedendo qualitativamente à sua disposição relativamente ao sujeito central e dos membros entre si. Quanto à densidade da rede ${ }^{4}$, que se refere, portanto, ao grau de conexão entre os membros da rede social pessoal, a maioria dos sujeitos da amostra apresenta redes coesas $(79,3 \%)$, tendo sido consideradas como fragmentadas aquelas que tinham níveis de densidade abaixo dos 80\% (exclusive). A Figura 1 mostra duas das configurações típicas que encontramos na nossa amostra.

Figura 1 - Representações das redes dos casos 12 e 27 da amostra

\footnotetext{
${ }^{4}$ Para analisar a densidade das redes de suporte social, usamos o UCINET versão 6.164 (BORGATTI; EVERETT; FREEMAN, 2002) e o NetDraw 2.072 (BORGATTI, 2002) para a representação das redes.
} 


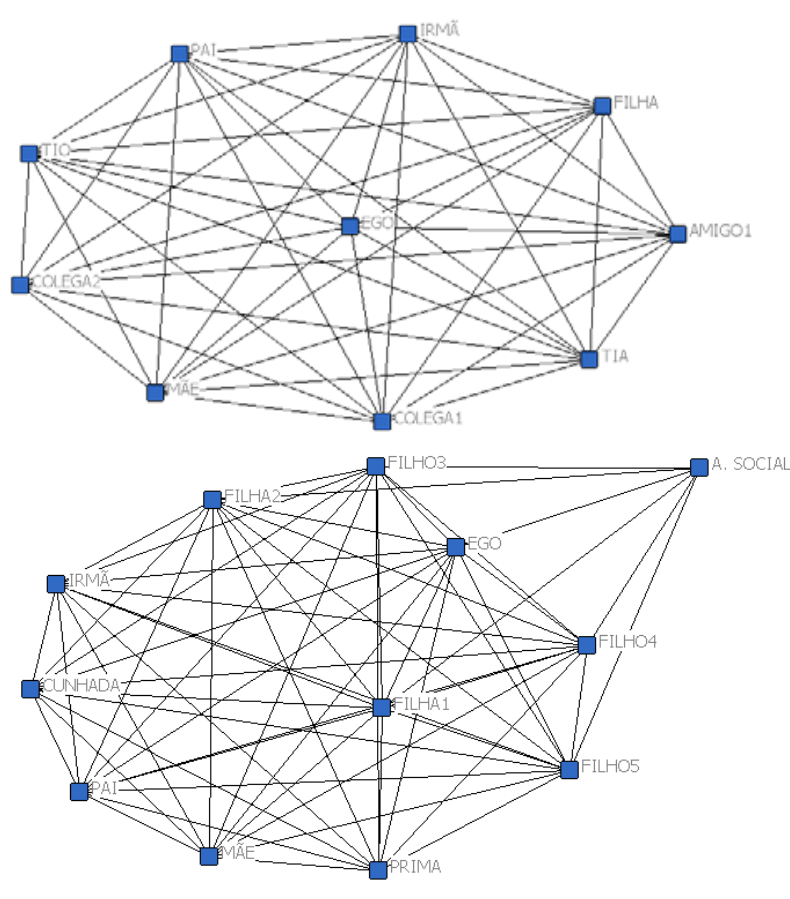

Fonte: elaborada pelos autores.

A rede do caso 12 (Figura 1) é constituída por 9 elementos, sendo uma rede coesa com $100 \%$ de densidade, composta por 3 campos: o das relações familiares, o das relações de amizade e o das relações de trabalho/estudo. 0 caso 27 (Figura 1), apresenta uma rede com 11 elementos, interconectados com um nível de densidade de 90,91\%, com apenas 2 campos: o das relações familiares e o das relações institucionais.

O apoio social recebido foi avaliado com base numa escala de Likert de cinco pontos, que reflete a frequência na qual o sujeito entende receber apoio emocional, material e/ou instrumental e informativo por parte dos elementos da sua rede, sendo que, quanto maior a pontuação, maior a frequência de suporte. Assim, verificamos que a amostra apresenta níveis moderados de apoio emocional (3); relativamente ao apoio material/instrumental e informativo, a média obtida é mais baixa (2,3 e 1,9, respectivamente), o que significa "pouco apoio".

A reciprocidade funcional é elevada, na medida em varia entre 4 e 5 , o que significa que essas mulheres dão apoio a alguns membros (4) (5) ou à maior parte dos membros da sua rede. 
Tabela 3 - Características Funcionais e Contextuais da Rede de Suporte Social

\begin{tabular}{llll}
\hline $\mathbf{n}=\mathbf{2 9 )}$ & $\mathbf{M}$ & $\boldsymbol{D P}$ & $\begin{array}{c}\text { Variação } \\
\text { Min - Máx }\end{array}$ \\
\hline Características funcionais da rede & & & $1-4$ \\
$\quad$ Frequência de suporte emocional & 3,03 & 0,746 & $1-4$ \\
$\quad$ Frequência de suporte material/instrumental & 2,38 & 0,783 & $1-3$ \\
$\quad$ Frequência de suporte informativo & 1,90 & 0,646 & $4-5$ \\
$\quad$ Reciprocidade funcional na rede & 4,62 & 0,494 & $1-3$ \\
$\quad$ Características contextuais da rede & & & $1-4$ \\
$\quad$ Frequência de contatos (ego com membros na rede) & 2,06 & 0,602 & 0,727 \\
$\quad \begin{array}{l}\text { Dispersão geográfica da rede (distância de residência } \\
\text { ego/membros) }\end{array}$ & 2,64 & &
\end{tabular}

M (média); DP (desvio-padrão). Fonte de Dados: IARSP-RS

Fonte: elaborada pelos autores.

A frequência de contatos entre o sujeito central e os membros da rede é elevada, já que os resultados obtidos variam entre os contatos diários (1) e os semanais (3), obtendo a média de 2, o que os situa nos contatos de algumas vezes por semana. Importa referir que, ao nível das relações familiares, a média de frequência de contatos é diária, assim como nas relações de trabalho e/ou de estudo e nas relações de vizinhança. Já com as relações de amizade e as institucionais é de algumas vezes por semana. As redes dos sujeitos da amostra apresentam uma dispersão geográfica da rede que varia entre elementos que residem na mesma casa (1) e os que residem numa distância de até $50 \mathrm{~km}$ (4), obtendo-se a média de 2,64, o que os situa entre contatos que decorrem com elementos da rede que vivem na mesma rua (2) e os que vivem na mesma terra (3).

\section{Discussão dos resultados}

Quanto ao perfil demográfico, a nossa amostra é constituída unicamente por mulheres, expressão do fato de a monoparentalidade ser uma condição vivida essencialmente no feminino (PERISTA, GOMES; SILVA, 1992; PEREIRINHA et al., 2008; WALL; LOBO, 1999). Sublinhe-se que $86,2 \%, 86,4 \%$ e $86,7 \%$ dessas famílias, nos censos de 1991, 2001 e 2011, respectivamente, eram constituídas por mulheres sós com filhos a seu cargo (MARINHO, 2014). Quanto à idade das inquiridas, verificamos ser de 38 anos em média, situando-se entre os 18 e os 61 anos de idade, sendo uma amostra heterogênea, média que se situa na faixa etária mais representativa para essas mulheres no inquérito censitário de 2011 (MARINHO, 2014). 
Em média, as mulheres da amostra vivem a monoparentalidade há 4 anos, tendo sido apontada como principal causa o divórcio ou a separação, sendo esta uma realidade com uma relevância estatística em Portugal cada vez mais acentuada (PORDATA; INE). É também uma situação mais frequente no grupo das mulheres, sendo que Vaz (1999) refere que depois de uma ruptura conjugal as mulheres têm mais dificuldades em refazer as suas vidas, enquanto os homens o fazem mais frequentemente e num período de tempo mais curto. Essa ideia parece estar presente quando $82,8 \%$ das inquiridas referiu não ter qualquer envolvimento afetivo, e só $13 \%$ manifestaram intenção de reconstruir família num modelo biparental.

Scarpellini e Carlos (2011) associam a perda da expectativa de reconstituição das suas vidas ao fato de essas mulheres serem provedoras e mães, subtraindo os seus desejos e a sua autorrealização em favor do cuidar da família. Quanto ao número de filhos que compõem o agregado familiar, a maioria das famílias inquiridas tem apenas um filho, embora a média de filhos na amostra seja de 2 filhos $(M=1,66)$, o que está em consonância com as tendências na demografia portuguesa e europeia das últimas décadas. A focalização nos filhos e no papel de mãe como reconhecimento identitário é um traço confirmado por Diogo e Roque (2002)

Relativamente ao nível de escolaridade das inquiridas, verificamos que a maior parte possui apenas o $1^{\circ}$ ou o $2^{\circ}$ ciclo do ensino básico (10 ao 6음 ano), o que revela um nível de escolaridade dominantemente abaixo da escolaridade obrigatória. No que concerne à condição perante o trabalho, a grande maioria encontra-se em situação de desemprego $(62,1 \%)$, sendo que as que se encontram inseridas profissionalmente $(34,5 \%)$ apresentam empregos precários e maioritariamente mal remunerados. Note-se que em caso de desemprego o risco de pobreza nessas famílias é extremo, sendo que dados da OCDE de 2010 sublinham um efeito cumulativo das duas vulnerabilidades, "na medida em que o maior risco de pobreza está associado a famílias monoparentais em que a figura parental está desempregada", colocando-as num nível de risco de 90,2\% (OCDE, 2011, apud UNICEF, 2013, p. 15).

Pereirinha et al. (2008) refere que Portugal apresenta, no contexto da União Europeia, uma das maiores taxas de atividade feminina. Não obstante a elevada participação feminina no mercado de trabalho pago, tem sido uma realidade a menor 
qualidade de emprego das mulheres, concentradas em setores mais desqualificados, com menor estatuto remuneratório, vínculos contratuais mais precários e formas diversas de desigualdade e de discriminação de gênero (FERREIRA; MONTEIRO, 2013). Relativamente à principal fonte de rendimentos dessas famílias monoparentais analisadas, apuramos que $31 \%$ das inquiridas beneficiam-se do RSI combinado com outras fontes de rendimento (abonos de família, pensões de alimentos, subsídio de desemprego, ajudas familiares ou trabalho).

O estudo de Rodrigues (2010, p. 174) assinala esta tendência na feminização das titulares da medida do RSI, refletindo "a importante presença de famílias monoparentais de lado feminino na tipologia familiar predominante na medida". A prestação pecuniária revela-se muitas vezes insuficiente, constituindo, no entanto, um dos principais meios de subsistência dessas famílias, tal como num estudo anterior de Tavares (2006). Ainda assim, a política de mínimos garantidos é referida como "tábua de salvação" num estudo de Diogo e Roque (2002) com 40 famílias monoparentais femininas dos Açores e da Madeira beneficiárias da medida atualmente designada por RSI, medida tida como fundamental por tais mulheres para fazer em face às necessidades mais prementes. Num contexto de corte acelerado e intenso do número de beneficiários(as) e dos montantes de referência da medida, por efeito da austeridade imposta pelo XIX Governo Constitucional de Portugal, muitas famílias monoparentais ficaram ainda mais desprotegidas. Outras opções políticas têm apresentado movimentos contraditórios, pois, apesar da majoração do abono de família e do subsídio de desemprego (em 2012) para essas famílias, a percentagem do valor do Indexante de Apoios Sociais, que determina o valor de referência para o seu cálculo, de dedução à colecta, diminui, em 2013, de 80 para 70\%, o que se traduz numa redução do apoio do Estado (UNICEF, 2013).

Um dos aspectos que nos chamou a atenção foi o fato de a maioria das famílias não receber Pensão de Alimentos Devidos a Menores (62\%), assim como na amostra do estudo anterior, em que $90 \%$ dos progenitores não a assumiam (TAVARES, 2006), nem sempre sendo entendida pelas inquiridas como um direito de parentalidade perante a criança. A medida do RSI pode, nesses casos, ser importante, dado que informa e sensibiliza essas famílias sobre a existência de tal direito. 
O Abono de Família Majorado foi uma medida incluída no Plano Nacional de Ação para a Inclusão 2006-2008, integrada até a atualidade como política de segurança social, que teve como primeira prioridade "combater a pobreza das crianças e dos idosos, através de medidas que assegurem os seus direitos básicos de cidadania". Acontece que na nossa amostra verificamos que apenas $34,5 \%$ das inquiridas auferia desse direito, sendo que a maioria o desconhecia, tendo-o reclamado posteriormente. Hespanha et al. (2002, p.42) haviam já sublinhado essa característica num estudo com população em exclusão social, assinalando que "a população desconhece os seus direitos sociais, ignora os serviços existentes [...] e tem uma profunda dificuldade em lidar com os processos de acessos aos benefícios e serviços sociais que Ihes são destinados".

A iliteracia de direitos ficou assim destacada como característica da amostra em estudo e está fortemente relacionada à falta de sentido de direitos, compondo uma "cidadania condicionada" e mitigada (LEWIS, 1998). Na literatura encontramos testadas três ideias fundamentais relativamente a essa questão. A primeira é a de que a existência e ampliação de direitos legais é muito importante, uma vez que a regulamentação faz realçar o sentido de direitos, isto é, quanto mais legislação existir, nesse caso, mais as pessoas sentem que determinado direito lhes assiste. No entanto, tal não significa que as pessoas automaticamente os reconheçam, conheçam e utilizem (LEWIS, 1998). A outra ideia é a de que, quanto maior é o sentido de direitos, maior será o uso dos direitos existentes, e quanto maior é o uso dos direitos existentes, maior será o sentido de direitos (DULK; PEPER, 2007). Por fim, temos a ideia de que o conhecimento dos direitos existentes, a sua literacia, aumenta o sentido de direitos e o seu uso (DULK; PEPER, 2007).

Essas famílias declaram sentir diversas dificuldades, sendo as econômicas as mais destacadas, seguindo-se a educação dos filhos. Quanto ao primeiro aspecto, parece-nos que a vulnerabilidade econômica associada a problemas expressos de empregabilidade se conjugam, favorecendo o que Perista, Gomes e Silva (1992) referem como exposição a um risco de pobreza duplo - a posição dessas mulheres no mercado de trabalho é mais débil e são economicamente mais vulneráveis perante a separação ou o divórcio. Quanto ao segundo aspecto, Alarcão (2002, p. 215) alude que "ao nivel do subsistema parental as dificuldades têm sido fundamentalmente equacionadas em termos da impossibilidade de partilhar tarefas e de recorrer ao suporte que a complementaridade de papéis empresta à 
tarefa educativa que os pais assumem face aos filhos". Tais dificuldades parecem residir sobretudo no fato de terem que decidir e gerir sozinhas a melhor educação a dar aos filhos.

A maioria identifica dificuldades para as quais não consegue apoio $(64,5 \%)$, o que nos coloca questões relativas à (des)proteção social nas políticas sociais existentes. As conclusões de um trabalho de Sílvia Portugal (2008) sobre políticas familiares assinalam a contradição entre o forte investimento simbólico e discrusivo na família por parte das políticas sociais e a efetiva intervenção estatal e a escassez de ação manifestada na legislação, nas transferências monetárias e nos equipamentos sociais.

Em relação às prestações familiares, destaca-se: 1 ) o baixo investimento que as políticas públicas fazem nesse domínio, no conjunto das políticas sociais; 2) o seu baixo valor pecuniário e o reduzido impacto nos orçamentos familiares; 3) a introdução do princípio de seletividade na atribuição (PORTUGAL, 2008). Essa ruptura com o princípio da universalidade é tanto mais problemática se tivermos em conta os objetivos de favorecer as famílias de mais baixos rendimentos e as famílias numerosas, apontando para um impacto muito reduzido, quer em termos dos orçamentos familiares, quer em termos de justiça social (WALL, 2004).

\section{Rede de Suporte Social}

Referente às redes sociais de apoio, verificamos que nesses agregados as redes são pequenas, marcadamente familistas (LUCAS, GUADALUPE, ARRIAGA, 2013; PORTUGAL, 2014) e maioritariamente coesas, tendo em conta que a sua composição é essencialmente baseada no parentesco, em que todos se conhecem e estão em interconexão (GUADALUPE, 2009). Verificamos que as redes são menos coesas, ou mesmo fragmentadas, quando o progenitor se encontra inserido no mercado de trabalho, englobando na sua rede colegas de trabalho, o que favorece uma maior variedade de recursos e um menor controle e regulação nas relações interpessoais.

Apesar de muito recíprocas, a nível funcional, verifica-se uma disponibilidade moderada de apoio emocional, mas uma muito menor disponibilidade de apoios a nível material e instrumental, assim como em termos informativos. Isso pode indicar que a rede não é muito efetiva no suporte oferecido. A provisão informal é sobretudo referida como importante para as famílias a nível financeiro e na guarda dos filhos (FAVARO, 2009). No 
entanto, a acessibilidade da rede, tendo em conta a frequência de contatos e a proximidade entre os elementos, facilita o acesso ao suporte e à monitorização das variações das necessidades de suporte (GUADALUPE, 2009).

Esse suporte social da família extensa, assim como de respostas sociais comunitárias, ou a eficácia das políticas sociais torna-se fulcral, já que a família monoparental tem as mesmas funções, papéis e responsabilidades da família nuclear: oferecer possibilidades de desenvolvimento aos seus membros e lidar com problemas e outras crises do seu ciclo de vida, que apresenta características particulares (VAZ; RELVAS, 2002).

No entanto, Pereirinha et al. (2008) referem que nas famílias economicamente mais carenciadas as redes informais de entreajuda familiar são menos intensas. Ou seja, aquelas que beneficiam de menor apoio informal são concomitantemente as famílias mais necessitadas, com menos recursos educativos, dos segmentos menos qualificados e com menores rendimentos, sendo que Hespanha et al. $(2002$, p. 46) afirma que "os fatores que atingiram os indíviduos na sua capacidade de resposta, afetaram igualmente as suas redes de solidariedade primárias". Portugal (2008) indica que geralmente são ativados os laços da parentela restrita, mobilizando sobretudo as mulheres da família, num claro traço de feminização da ajuda. Mesquita (2012), num estudo com 20 famílias monoparentais femininas brasileiras em situação de pobreza, considera estes arranjos familiares como altamente vulneráveis, sendo famílias muito propensas a situações de risco e à incerteza, o que acontece geralmente por terem acesso a um sistema precário de proteção social.

\section{Conclusões}

Apesar das limitações e da especificidade da amostra, podemos afirmar que a situação de parca inserção no mercado de emprego dessas famílias, as redes de suporte informal muito restritas e circunscritas às relações familiares - com níveis elevados de reciprocidade e de apoio emocional, mas mais baixos na provisão social de suporte instrumental e de suporte informativo -, assim como o fraco nível de reconhecimento, acesso e efetivação dos direitos dessas famílias, deixam uma forte margem de desproteção social que pode favorecer trajetórias marcadas pela desqualificação, desfiliação e exclusão sociais. 
Uma rede informal de recursos escassos também não garante uma ação compensatória em face à insuficiência de apoio por parte das políticas públicas, cada vez mais seletivas e restritivas na proteção oferecida. Nesse sentido, os decisores deveriam refletir no sentido de reforçar políticas públicas que promovam uma efetiva proteção social, uma real possibilidade de conciliação da vida ativa de trabalho com o acompanhamento de suas crianças e de seus jovens e favorecer a igualdade de oportunidades tanto para essas mulheres e mães quanto para seus filhos. Tais políticas têm necessariamente que ir para além do alívio da intensidade da privação material, sob pena de apenas contribuirem para a manutenção de alguma dignidade humana e de reproduzirem socialmente a vulnerabilidade social de raiz estrutural na qual a monoparentalidade é um dos pormenores.

As tensões, as dissonâncias e as paradoxalidades das exigências colocadas às famílias e aos sujeitos na contemporaneidade parecem agudizar-se quando temos famílias de educador único, sobretudo quando o outro progenitor se demite dos seus deveres. As mulheres e as crianças de famílias monoparentais em situação de vulnerabilidade social carecem de especial atenção na relação com a ocupação ou com o trabalho e na relação com as respostas sociais comunitárias, pois apresentam características e necessidades particulares que não devem ser escamoteadas. É também fundamental um reforço de estratégias de intervenção social emancipadoras, nesse contexto, com focalização individual, mas sobretudo coletiva, que integrem um forte componente de advocacia social, favorecendo a cidadania.

\section{Referências}

ALARCÃO, M. (Des)equilibrios familiares.2. ed. Coimbra: Quarteto, 2002.

BORGATTI, S. P. NetDraw: Graph visualization software. Harvard: Analytic Technologies, 2002.

BORGATTI, S. P.; EVERETT, M. G.; FREEMAN, L. C. Ucinet para Windows: Software for social network analysis. Harvard: Analytic Technologies, 2002.

BRANCO, F. A face lunar dos direitos sociais: virtualidades e limites do RMG como direito de cidadania em Portugal. 2001. Tese (Doutorado em Serviço Social) - Pontifícia Universidade Católica de São Paulo, São Paulo, 2001. 
CARVALHO, L. Famílias chefiadas por mulheres: relevância para uma política social dirigida. Serviço Social e Sociedade, São Paulo, v. 19, n. 57,p. 74-98, 1998.

CÓRDON, J. A. F.; SOLER, C. T. Las familias monoparentales en España. Revista Española de Investigaciones Sociológicas, Madrid, n. 83, p. 52-85, 1998.

CORREIA, I. M. Familias monoparentais: uma familia, um caso... Revista Portuguesa de Clínica Geral, Lisboa, v. 18, n. 4, p. 18-242, 2002.

COSTA, A. B. et al. Um olhar sobre a pobreza. Vulnerabilidade e exclusão social no Portugal contemporâneo. Lisboa: Gradiva, 2008.

DIOGO, F.; ROQUE, R. Vidas no feminino: um estudo dos impactos biográficos do RMG nas famílias monoparentais femininas. Lisboa: Instituto para o Desenvolvimento Social, 2002.

DULK, L. D.; PEPER, B. Working parent's use of work-life policies. Sociologia, Problemas e Práticas, Lisboa, n. 53, p. 51-70, 2007.

FAVARO, C. S. Ser pai e mãe ao mesmo tempo: organização doméstica, estrategias familiares e redes sociais de mulheres chefes de domicilios monoparentais. 2009. $159 \mathrm{fls}$. Dissertação (Mestrado em Demografia) - Universidade Estadual de Campinas, Campinas. $2009 . \quad$ Disponível em:<http://www.bibliotecadigital.unicamp.br/document/ ?code $=000447042>$. Acesso em: 15 maio 2014.

FERREIRA, P. M.; ABOIM, S. Modernidade, laços conjugais e fecundidade: a evolução recente dos nascimentos fora do casamento. Análise Social, Lisboa, v. 37, n. 163, p. 411446, 2002.

FERREIRA, V.; MONTEIRO, R. Trabalho, igualdade e diálogo social: estratégias e desafios de um percurso. Lisboa: CITE, 2013.

GERARDO, F. Maternidade na adolescência forma de inclusão e/ou exclusão social. In: CONGRESSO LUSO-AFRO-BRASILEIRO DE CIÊNCIAS SOCIAIS: A QUESTÃO SOCIAL NO NOVO MILÉNIO, 8. 2004, Coimbra. Anais... Coimbra: UNIRIOJA, 2004. p. 105.

GOLOMBOK, S. Parenting: What really counts? East Sussex: Routledge, 2000.

GOMES, A. Retrato de familia. Xis, v. 238, p. 8-9, 2003.

GUADALUPE, S. Intervenção em rede: serviço social, sistémica e redes de suporte social. Coimbra: Imprensa da Universidade de Coimbra, 2009.

HESPANHA, P. et al. Globalização insidiosa e excludente. Da incapacidade de organizar respostas à escala local. In: HESPANHA,P.; CARAPINHEIRO, G. Risco social e incerteza: pode o estado recuar mais? Porto: Afrontamento, 2002. p. 25-54.

INSTITUTO DA SEGURANÇA SOCIAL - ISS. Relatório anual de 2008 do rensimento social de inserção. Lisboa, 2009. Disponível em:<http://www4.segsocial.pt/documents/10152/13308/rsi_relatorio_anual_2008>. Acesso em: 16 fev. 2014. 
INSTITUTO NACIONAL DE ESTATÍSTICA - INE. Famílias nos censos 2011: diversidade e mudança. Destaque: Informação à Comunicação Social, Lisboa, nov. 2013. Disponível em: $<$ https://www.ine.pt/xportal/xmain?xpid=INE\&xpgid=ine_destaques\&DESTAQUESdest_b oui=206614267\&DESTAQUESmodo=2\&xlang=pt>. Acesso em: 30 jun. 2014.

KAUFMANN, J. C. Famille et pauvreté en Europe. Colloque poverty and social exclusion in the European Community, Commission des Communautés Européennes. GrandeBretagne: Bath, 1990.

LEWIS, S. O sentido dos direitos a apoios para a conciliação entre o trabalho e a vida familiar: o caso do Reino Unido. Sociologia, Problemas e Práticas, Lisboa, n. 27, p. 27-39, 1998.

LOYOLA, M. A. Sexualidade e medicina: a revolução do século XX. Caderno de. Saúde Pública, Rio de Janeiro, v. 19, n. 4 Disponível em:<http://dx.doi.org/10.1590/\$0102311X2003000400002>. Acesso em: 30 jun. 2014.

LUCAS, M.; GUADALUPE, S.; ARRIAGA, S. Perceção de competências em famílias monoparentais femininas. Mosaico: Journal of the Spanish Federation of Family Therapy Associations, Espanha, n. 56, p. 115-127, 2013.

MARINHO, S. Famílias monoparentais: linhas de continuidade e de mudança. In: DELGADO, A.; Wall, K. (coord). Famílias nos censos 2011: diversidade e mudança. Lisboa: Instituto Nacional de Estatística e da Imprensa de Ciências Sociais, 2014.

MESQUITA, A. A. Proteção social na alta vulnerabilidade: o caso das famílias monoparentais femininas. 2012. 219 fls. Tese (Doutorado em Ciências Políticas Públicas Estratégias e Desenvolvimento) - Instituto de Economia, Universidade Federal do Rio de Janeiro, Rio de Janeiro, 2012.

PACHECO, A. L. P. B. Mulheres pobres e chefes de família. Tese (Doutorado em Psicossociologia de Comunidade e Ecologia Social) - Instituo de Psicologia, Universidade Federal do Rio de Janeiro, Rio de Janeiro. 2005. Disponível em:<http://teses.ufrj.br/IP_D/AnaLuciaPaesDeBarrosPacheco.pdf>. Acesso em: 10 maio 2014.

PEREIRINHA, J. A. et al. (Coord.) Género e pobreza: impacto e determinantes da pobreza no feminino. Lisboa: CIG-Comissão para a Cidadania e Igualdade de Género, 2008. Disponível em: <http://www.cig.gov.pt/siic/pdf/2014/siic-Genero_e_Pobreza.pdf>. Acesso em: 10 maio 2015.

PERISTA, H.; GOMES, E.; SILVA, M. A pobreza no feminino na cidade de Lisboa. Lisboa: Organizações não governamentais do conselho consultivo da Comissão para a Igualdade e para os Direitos das Mulheres. 1992.

PORDATA. Base de Dados de Portugal Contemporâneo. Disponível em: <http://www.pordata.pt/>. Acesso em: 10 maio 2014. 
PORTUGAL, S. As mulheres e a produção de bem-estar em Portugal. Coimbra: Oficina do CES-Centro de Estudos Sociais da Universidade de Coimbra, 2008. n. 319.

PORTUGAL, S. Famílias e redes sociais, ligações fortes na produção de bem-estar. Coimbra: Almedina. 2014.

PORTUGAL, S. Políticas de família. Revista Crítica de Ciências Sociais, Coimbra, n. 56, p. 8198, 2000.

PRZYBYSZ, J. Articulando os espaços privado e público: gênero e famílias monoparentais femininas.Terr@Plural, Ponta Grossa, v.3, n. 1, p. 29-39, 2009.

REAPN - REDE EUROPEIA ANTI-POBREZA. Indicadores sobre a pobreza: Portugal e União Europeia. Porto, 2009.

RELVAS, A. P. O ciclo vital da família: perspectiva sistémica. Porto: Afrontamento, 1996.

RODRGUES, E. V. Escassos caminhos: os processos de imobilização social dos beneficiários do rendimento social de inserção. Porto: Afrontamento, 2010.

SCARPELLINI, M.; CARLOS, V. Y. Monoparentalidade Feminina e Vulnerabilidade Social: a realidade de mulheres chefes de família no município de Apucarana.SIMPÓSIO GÊNERO E POLÍTICAS PÚBLICAS, 2.,2011, Londrina. Anais... Londrina: UEL, 2011.

SORENSEN, A. Single mothers, low income end women's economic risks. The case of Sweden, West Germany and the United States. Madrid, 1990. Comunicação ao Seminário da ISA, 1990.

TAVARES, S. M. C. Monoparentalidade como fator acrescido de exclusão social: a situação específica do Concelho de Cantanhede. Relatório de Estágio da Licenciatura em Serviço Social. Coimbra: ISMT, 2006.

TAVARES, S. M. C. Famílias Monoparentais em situação de vulnerabilidade social - Estudo sobre as representações sociais, satisfação familiar, recursos familiares e rede de suporte social das famílias monoparentais apoiadas pelo Banco de Recursos Colmeia de Cantanhede. Dissertação de Mestrado em Psicologia Clínica. Coimbra: ISMT, 2009.

TORRES, A. Mulheres divorciadas: um contributo para o estudo dos processos de mudança na familia. In: CONGRESSO PORTUGUÊS DE SOCIOLOGIA, 1., 1989, Lisboa. Atas... Lisboa: Fragmentos, 1989.

TORRES, A. O divórcio em Portugal: ditos e interditos: uma análise sociológica. Oeiras: Celta. 1996.

UNICEF. Comité Português. As crianças e a crise em Portugal: vozes de crianças, políticas públicas e indicadores sociais. Lisboa, 2013. <http://www.unicef.pt/as-criancas-e-a-criseem-portugal/files/Relatorio-Unicef.pdf>. Acesso em: 20 jun. 2014. 
VAZ, C. P.; RELVAS, A. P. Monoparentalidade: uma família à parte ou uma parte de uma família. In. RELVAS, A. P.; ALARCÃO. M. (Org.). Novas formas de familia. Coimbra: Quarteto. 2002. p. 248-298.

VAZ, C. R. Uma familia à parte ou a parte de uma familia? Estudo psicossociológico sobre a familia de educador único. 1999. Dissertação (Mestrado em Família e Sistemas Sociais) xxxx. Instituto Superior Miguel Torga, Coimbra, 1999.

VITALE, M. A. F. Famílias monoparentais: indagações. Serviço Social e Sociedade, São Paulo, Ano XXIII, n. 71, p. 45-62, 2002.

WALL, K. Developments in family policy in Portugal in 2003. Lisboa: ICS. 2004.

WALL, K. Famílias monoparentais. Sociologia, Problemas e Práticas, Lisboa, v. 43, p. 51-66, 2003.

WALL, K.; LOBO, C. Familias monoparentais em Portugal. Análise Social, Lisboa, n. 150, p. 123-145, 1999.

Recebido em: 18/05/2015

Aprovado em: 25/06/2015 